\title{
Effects of Emotional Stress on Neuroendocrine and Autonomic Functions in Skydiving
}

Messina Giovanni ${ }^{2}$, Anna Avalenzano², Fiorenzo Moscatelli², Antonio I Triggiani², Laura Capranica ${ }^{3}$, Antonietta Messina ${ }^{1}$, Laura Piombino ${ }^{1}$, Domenico Tafuri ${ }^{4}$, Giuseppe Cibelli ${ }^{2}$ and Marcellino Monda ${ }^{1^{*}}$

${ }^{1}$ Department of Experimental Medicine, Section of Human Physiology and Clinical Dietetic Service, Second University of Naples, Naples, Italy

${ }^{2}$ Department of Biomedical Sciences, University of Foggia, Foggia, Italy

${ }^{3}$ Department of Movement and Sport Sciences, University of Rome, Rome, Italy

${ }^{4}$ Department of Motor Sciences and Wellness, University of Naples, Naples, Italy

\begin{abstract}
By using a psycho-physiological approach we investigated the stress response during parachute jumping, a wellcharacterized stress model to study emotional and physical stress in humans. Besides the observation of hormone reactivity in response to such a short-term stressful event, this study focused on the correlations among competitive state anxiety components, hormonal and autonomic responses. Seven male sport-parachutists, aged $35.7 \pm 17.5$ years, took part in the study after giving their informed consent. Neuroendocrine and autonomic variables were measured $12 \mathrm{~h}$ before jumping (basal), within $60 \mathrm{~s}$ (jump) and $90 \mathrm{~min}$ after touching the ground (post-jump). Prior to boarding, participants were administered the Competitive State Anxiety Inventory-2 (CSAI-2) questionnaire. Salivary cortisol (Cort) and $\alpha$-amylase (A-A) concentrations were measured by spectrophotometry using commercial kits. For heart rate (HR) and galvanic skin response (GSR) assessments data were acquired by holter recording, within an interval time of $5 \mathrm{~min}$ following saliva collection. Parachute jumping led to a strong response of Cort, A-A, as well as HR and GSR, as shown by the values noted as basal and at jump, meaning that the psychological arousal linked to this condition acts on different systems. In examining bioumoral correlates and psychological measures of stress and anxiety we found correlations between neuroendocrine parameters and anxiety components. However, no relationship between Cort and somatic or cognitive anxiety was noted, suggesting that this physiological measure is not a good index of stress during parachuting. As revealed by the differences in cognitive or somatic state anxiety, stress related to sport parachuting differentially affected salivary indices. Alpha-amylase seems to be a better physiological indicator than cortisol to examine the relationship between neuroendocrine parameters and state anxiety components. Finally, this is the first report that GSR significantly correlated with A-A and the somatic component of competitive state anxiety, confirming its potential to provide researchers with a tool for objectively measuring stress during operational conditions. On the whole, these findings have contributed to our understanding of hormone-behavior relationships.
\end{abstract}

Keywords: Stress; Anxiety; Cortisol; a-amylase; Saliva; GSR; Parachute jumping; Autonomic nervous system; CSAI-2

\section{Introduction}

Many studies recognize the hypothalamic-pituitary-adrenal (HPA) axis, the sympathetic- adreno-medullary (SAM) and the sympathoneural (SN) systems as the main components of the psychobiology of stress, by means of both the secretion of glucocorticoids (e.g., cortisol) and the release of catecholamines into the blood stream [1-5]. Although these systems are physiologically interconnected, they show different characteristic responses to stress and associations with behavior. In fact, neuroendocrine and autonomic responses can differentially react to stressors, depending on the type and intensity of the stressor itself and interpreted in light of individual experience [6-7]. Separate factors regulate cortisol and catecholamines release. Cortisol is related to the amount of threat or distress produced by a task [8], which is especially relevant in situations inducing ego-involvement, novelty and unpredictability, leading to negative affective states [9]. By contrast, SAM activation appears to be related to the amount of effort put in action by the subject in a task and associated with feeling of alertness and action proneness [10]. Therefore, the excretion rates of cortisol and catecholamines could be seen as indicators of the effect of different task and environmental demands on healthy people [11-14]. Emotions represent individual's perception of personally relevant environmental interactions, including not only challenges and threats, but also the ability to respond to them [15]. Viewed as such, an adequate emotional response to stress is based on the selection, from a broad behavioral repertoire, of an optimal response and the inhibition of less functional ones to constantly changing environmental demands. Individual differences in response to stressors can be measured non-invasively in saliva. Measurement of the activity of the HPA axis via salivary cortisol is well established [16]. More recently, the salivary $\alpha$-amylase, an enzyme produced locally by salivary glands, has become feasible, as a marker of the adrenergic component of the stress response $[17,18]$. Salivary $\alpha$ - amylase levels increase under stressful conditions known to increase plasma catecholamines [19-22]. The levels of $\alpha$-amylase in the body have been used as an effective measure of stress, including social stress, such as performance in front of an audience [23-25], testing [26] ,competition [27,28], and physical stress [29-31]. Noninvasive measurement of activity in the $\mathrm{SN}$ system is also possible via skin conductance. The GSR has long been considered a measure of physiological and mental stress [32]. This method consists in capturing

*Corresponding author: Marcellino Monda, Department of Experimental Medicine, Section of Human Physiology, and Clinical Dietetic Service, Second University of Naples, Via Costantinopoli 16, 80138 Naples, Italy, Tel: +39 +81566 5804; Fax: +39 +81 5667500; E-mail: marcellino.monda@unina2.it

Received March 26, 2015; Accepted April 20, 2015; Published April 27, 2015

Citation: Messina G, Avalenzano A, Moscatelli F, Triggiani Al, Capranica L, et al. (2015) Effects of Emotional Stress on Neuroendocrine and Autonomic Functions in Skydiving. J Psychiatry 18: 280 doi: 10.4172/2378-5756.1000280

Copyright: (c) 2015 Messina G, et al. This is an open-access article distributed under the terms of the Creative Commons Attribution License, which permits unrestricted use, distribution, and reproduction in any medium, provided the original author and source are credited 
the autonomic nerve response as a parameter of the sweat gland function, by measuring the electrical resistance of the skin. As a matter of fact, the relationship between stress and anxiety is unequivocal. Feelings of anxiety are stressful and exposure to stressors induces neuroendocrine activation associated with increased anxiety. Morris et al. [33] have proposed a multidimensional view of anxiety, which differentiates anxiety into physical and mental components. Consistent with this multidimensional theory of anxiety, Martens et al. [34] developed a sport anxiety scale, the CSAI-2, to differentiate between the cognitive and somatic components of state anxiety and self-confidence, when investigating anxiety components during a competition. The functional relationships between psychological stress reactions, SN and SAM responses and HPA axis activation have been extensively investigated both during experimental laboratory sessions [16,35-37]. Competitive parachute jumping is an acute, intensive stress situation, which has been employed by several investigators as a real-life stress situation [32,38-40]. Sport parachuting is characterized by a markedly accentuated sympathetic activation, as shown by the increase in heart and respiration rates [41] and a higher degree of self-rated arousal during jumps [42]. The increase in HR can be principally ascribed to emotional tension and a state of anticipation, rather than to physical stress [43-45]. The process of coping with anxiety and emotion in this situation appeared to be characterized by specific hormone patterns, particularly elevated catecholamines and suppressed levels of cortisol and testosterone [19]. Time kinetics of the endocrine response in inexperienced parachutists showed a significant increase in epinephrine concentrations during the jump itself, while norepinephrine, cortisol, growth hormone, prolactine, and thyroid- stimulating hormone peaked with a latency of 10-20 min. Apart from cortisol and TSH concentrations, which were still elevated $1 \mathrm{~h}$ after the stress event, plasma levels of the other endocrine variables normalized within $1 \mathrm{~h}$ following the jump [46-49]. There are studies on aggressive behavior that indicate a diverse stress response between SNS and HPA; using a psycho-physiological approach to investigate competitive stress during parachute jumping, this study aimed at providing indications on the relationship between anxiety components and hormonal responses and determining whether the GSR can be adopted as a tool for objectively measuring the stress response during operational conditions. Since sportive activity simulates some situations of aggressive behavior, the purpose of this study was to investigate whether the SNS and the HPA axis would show parallel or divergent stress response patterns in a session of parachute jump. In general, there are not studies about the effect of skydiving on both the SNS and HPA axis.

\section{Methods}

\section{Subjects}

Seven healthy adult male sport-parachutists, with different level of experience, took part in the study. All participants were in good health, as defined by the absence of cardiovascular disease, or had no history of endocrine disorders and were not taking any medication. Prior to data collection, the purpose of this study was explained thoroughly and informed consent was obtained from each participant, according to the Declaration of Helsinki. The study has been approved by the Ethics Committee of the Second University of Naples. The sample size is conditioned by the fact that it is preferable to test the reactions in the same day with identical environmental conditions and weather.

\section{Study protocol}

The study protocol consisted of one day of testing in which each participant was asked to continue his normal work and leisure activities.
The subjects were instructed to have food and beverages as usually and to sleep a sufficient amount of hours. Jumps were performed between $1845 \mathrm{~h}$ and $1915 \mathrm{~h}$. The altitude reached by the aircraft at the time of the jump was 4500 feet, allowing for a free fall of $60 \mathrm{~s}$ before the parachute was opened and approximately $90 \mathrm{~s}$ until touching the ground.

\section{Hormonal assay}

Salivary samples were collected in the first 30 min immediately after awakening (basal), within $60 \mathrm{~s} \mathrm{(jump);} \mathrm{and} 90 \mathrm{~min}$ after touching the ground (post-jump), by means of cotton- swabs (Salivette, Sarstedt, Rommelsdorf, Germany). Participants were asked to place the cotton swab into their mouth for at least 2 min while chewing and then insert it back into a special plastic tube. Samples were returned as soon as possible to the laboratory and stored at $-20^{\circ} \mathrm{C}$ for further free cortisol and $\alpha$-amylase assay. The absence of blood contamination was checked by a salivary blood contamination kit (Salimetrics LLC, State College, PA, USA). The saliva collecting tubes were centrifuged at $1500 \mathrm{x} \mathrm{g}$ for $15 \mathrm{~min}$ at $4^{\circ} \mathrm{C}$. Fifty to $100 \mu \mathrm{l}$ of saliva were used for duplicate analysis. All samples were tested in the same series to avoid any variations between tests. The Cort and A-A concentrations were measured by commercial kits (Salimetrics LLC, State College, PA, USA), according to manufacturers' instructions. The intra-assay and inter-assay coefficients of variation were $3.7 \%$ and $7.5 \%$ for Cort, $4.2 \%$ and $7.8 \%$ for A-A. A standard plate reader (Power Wave XS, Bio-Tech Instruments, US) was used for salivary determination by $450 \mathrm{~nm}$ filters.

\section{Measurement of $\mathrm{HR}$ responses and GSR}

Within an interval time of 5 min following saliva collections, HR responses and GSR data were recorded. Each participant wore a chest belt hard-wired to a digital R-R recorder (Polar Electro Oy, Kempele, Finland), where the QRS-signal wave-form R-R signal was sampled at the resolution of $1 \mathrm{~ms}$. The HR (beats min-1) was calculated according to the following Formula:

$\mathrm{HR}=60 \cdot \mathrm{R}-\mathrm{R}$ interval-1 where, $\mathrm{R}-\mathrm{R}$ interval was converted into seconds.

The GSR parameters were measured simultaneously using the SenseWear Pro Armband" (version 3.0, Body Media, Inc. PA, USA), which was worn on the right arm over the triceps muscle at the midpoint between the acromion and olecranon processes, as recommended by the manufacturer.

\section{Psychometric assessment}

Thirty min prior to entering the aircraft participants were administered the Italian version of the CSAI-2 questionnaire [50]. The CSAI-2 is a 27-item inventory that measures cognitive state anxiety (CA), somatic state anxiety (SA) and self-confidence (S-C) in a competitive setting [34]. Each subscale, consisting of 9 items, is rated on a scale from $1=$ "not at all" to $4=$ "very much so", resulting in scores ranging from 9 to 36 for each subscale. High scores on CA, SA and S-C indicate high levels of anxiety and self-confidence, respectively.

\section{Statistical analysis}

The statistical program Graph Pad Prism for Windows (v.5.01) (San Diego, CA, USA) was used for the analysis and treatment of the data. Physiological responses during the experimental session were analyzed using one-way analysis of variance (ANOVA) with repeated measurements, as well as the Student's t-test, when appropriate. When a significant $(\mathrm{p}<0.05) \mathrm{F}$ value emerged, the Bonferroni multiple comparisons test was performed to identify significant differences 
among measures. The Pearson correlation coefficient was used to ascertain the relationships among variables. When significant differences emerged, a linear regression analysis was performed. The Cronbach's alpha coefficient for internal consistency was calculated for the CSAI-2 scores, assuming an alpha value of $\geq 0.8$ as reliable. Data are reported as mean $(\mathrm{M})$ and standard deviation $(\mathrm{SD})$.

\section{Results}

\section{Physical characteristics}

The physical characteristics of the subjects participating in the study are presented in Table 1. Their ages ranged between 18 and 61 years and all were within $10 \%$ of their ideal body weight.

\section{Physiological responses to stress}

Physiological reactions of parachutists were investigated as a function of the sequence of events leading up to and following a jump. Variation in the range of basal values of both A-A and Cort were not associated with age, which is in keeping with consensus opinion that adrenal activity is not age-dependent.

Parachute jumping induced the expected significant increases in both autonomic and hormonal variables. The analysis of variance showed significant differences between the experimental conditions for Cort $[\mathrm{F}(2,18)=7.9, \mathrm{p}<0.01)$, A-A $(\mathrm{F}(2,18)=4.7, \mathrm{p}<0.05], \quad H R$ $[F(2,18)=21.7, p<0.01]$ and $G S R[F(2,18)=4.2, p<0.05]$, respectively. As shown in Figures $1 \mathrm{~A}$ and $1 \mathrm{~B}$, concentrations of $\mathrm{A}-\mathrm{A}$ and Cort rose in parallel, reaching peak values immediately after landing. Interestingly, the concentration of Cort fell to basal values within $90 \mathrm{~min}$, but the concentration of A-A remained significantly elevated $[\mathrm{F}(2,18)=4.7$, $\mathrm{p}<0.05$ ] after $90 \mathrm{~min}$ from touching the ground, with respect to basal values. Figures $1 \mathrm{C}$ and $1 \mathrm{D}$ show autonomic responses across each condition. Heart rates significantly increased from a basal mean of 67.4 \pm 9.8 beats $\alpha$ min- 1 to a peak value of $120.3 \pm 20.7$ beats min- 1 at the jump, corresponding to $51.4 \pm 13.2 \%$ of the individual's maximal $H R$. After touching the ground, HR dropped to values similar to the basal ones. No ventricular arrhythmias or ST segment abnormalities were recorded.

Significantly higher GSR levels were recorded at jump, suggesting high levels of stress. Accordingly with A-A changes, GSR levels remained significantly elevated after $90 \mathrm{~min}$ from touching the ground, as compared to basal values.

\section{Psychological responses to stress}

The CSAI-2 scores are presented in Table 2. The Cronbach's index of internal consistency for the three subscales showed good internal consistency $(\alpha=0.85-0.91)$. As shown in the table, S-C reached the highest scores, whilst absolute scores for CA and SA reached lower values, showing a similar trend. One-way ANOVA showed significant differences for $\mathrm{S}-\mathrm{C}$ and $\mathrm{SA}[\mathrm{F}(2,18)=55, \mathrm{p}<0.01]$ and for $\mathrm{S}-\mathrm{C}$ and $\mathrm{CA}$ scores $[F(2,18)=27.5, p<0.01]$, but not for $S A$ and CA scores.

\section{Correlations among measures}

Table 3 shows the correlation between physiological responses

\begin{tabular}{|c|c|c|c|c|}
\hline $\begin{array}{c}\text { Subjects } \\
\text { (n) }\end{array}$ & $\begin{array}{c}\text { Age (years) } \\
\mathbf{M} \pm \text { SD }\end{array}$ & $\begin{array}{c}\text { Weight (kg) } \\
\mathbf{M} \pm \mathbf{S D}\end{array}$ & $\begin{array}{c}\text { Height (cm) } \\
\mathbf{M} \pm \mathbf{S D}\end{array}$ & $\begin{array}{c}\mathbf{B M I} \mathbf{~ ( k g m ~}^{2} \text { ) } \\
\mathbf{M} \pm \mathbf{S D}\end{array}$ \\
\hline 7 & $35.7 \pm 17.5$ & $76.7 \pm 7.3$ & $174.9 \pm 10.1$ & $25 \pm 1.5$ \\
\hline
\end{tabular}

Table 1: Age and anthropometric values, expressed as mean \pm standard deviation. BMI: body mass index.
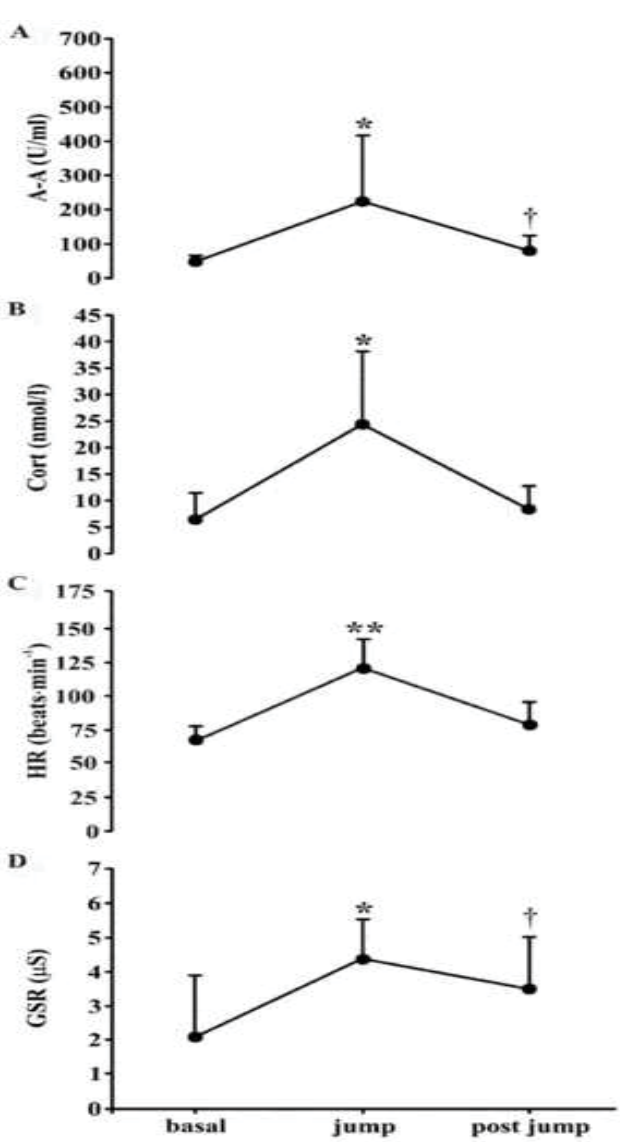

Figure 1: Hormonal and autonomic responses, Mean salivary a-amylase $(A-A)(A)$, Cortisol (Cort) (B), heart rate (HR) (C), and galvanic skin response (GSR) (D) responses to parachuting as a function of time-to event: at the morning of the jump (basal), after $60 \mathrm{~s}$ (jump) and $90 \mathrm{~min}$ from touching the ground (post- jump). ${ }^{*} p<0.05$; "* $p<0.01$ vs basal; ${ }^{\dagger} p<0.05$ vs basal. Graphs show \pm SD.

\begin{tabular}{|c|c|c|c|}
\hline Psychiological Instrument & & State Measure & \\
\hline CSAI-2 & CAt & SA & S-C \\
\hline & $\mathrm{M} \pm \mathrm{SD}$ & $\mathrm{M} \pm \mathrm{SD}$ & $\mathrm{M} \pm \mathrm{SD}$ \\
\hline & $13.6 \pm 3.4$ & $12.7 \pm 3.5$ & $27.7 \pm 1.9$ \\
\hline
\end{tabular}

Table 2: The CSAI-2 scores, values, expressed as mean \pm standard deviation.

\begin{tabular}{|c|c|c|c|c|c|c|}
\hline A-A & $\mathbf{0 . 0 3}$ & & & & & \\
\hline GSR & -0.17 & $0.71^{*}$ & & & & \\
\hline HR & $-0.80^{*}$ & -0.39 & -0.22 & & & \\
\hline CA & -0.02 & 0.55 & 0.25 & -0.30 & & \\
\hline SA & -0.18 & $0.89^{*}$ & $0.76^{*}$ & -0.24 & 0.33 & \\
\hline S-C & -0.18 & 0.54 & 0.43 & -0.02 & 0.47 & $0.82^{*}$ \\
\hline
\end{tabular}

Note: A-A, a amylase; Cort, Cortisol;HR, Heart Rate;GSR, galvanic Skin Response;CA, Cognitive Anxiety; SA, Somatic Anxiety; S-C, Self-Confidence. ${ }^{*} \mathrm{P}<0.05$; ${ }^{* *} \mathrm{P}<0.01$

Table 3: Pearson correlation coefficients among physiological responses and psychological variables at jump.

and psychological variables at jump. Significant correlations emerged between A-A and GSR $(\mathrm{r}=0.71, \mathrm{p}<0.05)$, and between Cort and HR $(r=-0.80, p<0.05)$. No correlation was found between A-A and Cort responses, and between HR, GSR or A-A responses. Regarding psychometric variables, SA scores significantly correlated with both A-A $(r=0.90, p<0.01)$ and GSR $(r=0.76, p<0.05)$. A significant 

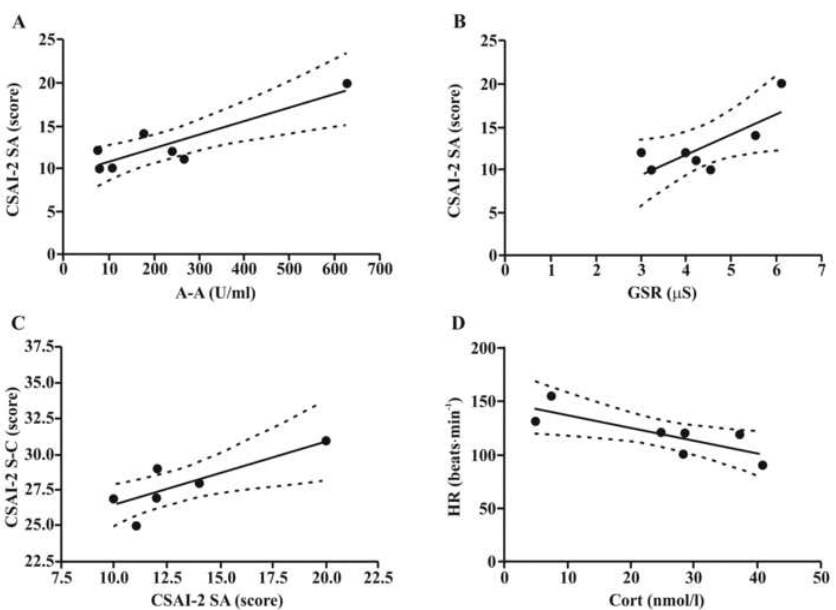

Figure 2: Regression analysis among physiological responses at jump and psychological variables.

Positive relationships between salivary a-amylase $(A-A)$ and somatic anxiety $(S A)$ values $(p<0.01)(A)$, galvanic skin response $(G S R)$ and $S A$ values $(p<0.05)(B)$, SA and self- confidence $(S-C)$ values $(p<0.05)(C)$, and negative relationship between cortisol (Cort) and heart rate $(H R)$ values $(p<0.05)(D)$ in parachutists at jump. Dotted line depicts $95 \%$ confidente interval.

relationship was also found between SA and S-C ( $\mathrm{r}=0.82, \mathrm{p}<0.05)$. As shown in Figure 2, subsequent regression analysis evidenced a linear relationship between $\mathrm{A}-\mathrm{A}$ and $\mathrm{SA}(\mathrm{r} 2=0.79, \mathrm{~F}=19.3, \mathrm{p}<0.01), \mathrm{GSR}$ and SA $(\mathrm{r} 2=0.58, \mathrm{~F}=7.0, \mathrm{p}<0.05), \mathrm{SA}$ and $\mathrm{S}-\mathrm{C}(\mathrm{r} 2=0.67, \mathrm{~F}=10.1, \mathrm{p}<0.05)$. Interestingly, the negative relationship between Cort and $\mathrm{HR}$ was confirmed $(\mathrm{r} 2=0.65, \mathrm{~F}=9.1, \mathrm{p}<0.05)$; while a positive trend was found between A-A and GSR ( $\mathrm{r} 2=0.51, \mathrm{~F}=5.2, \mathrm{p}=0.07$; data not shown).

\section{Discussion}

Few studies have examined both hormonal and autonomic responses throughout the course of a parachute jumping event and the state anxiety associated with such a performance [19,51]. A similar lack of information exists as to somatic and cognitive anxiety. In the present study, physiological measures were recorded from sport parachutists before and after a single jump session and compared with self-reported state anxiety ratings, arising the question whether differences in physiological responses would correspond to differences in subjective ratings of both SA, CA and S-C. Not infrequently, novice parachutists manifest a level of anxiety unrivaled by the behavior disorders. If taken out of this context, symptoms including cognitive and motor disorganization, ambivalence and perceptual denial, would rather suggest the presence of pathology. Conversely, experienced jumpers present an entirely different picture, in that if they experience anxiety, it is not evident. Therefore, in the present study subjects with different level of experience were used as their own controls. With respect to the overall results a great deal of uniformity across subjects was verified, indicating that particular organ systems react in an increasingly characteristic way once the stress is high. Emotions can be considered the result of two major components: a physiological arousal, which prepares the action and cognitive assessment of the environmental situation, which drives the behavioral response of the subject [52]. State anxiety, typical of sport situation, is the tendency to perceive competitive situations as dangerous and to respond accordingly with feelings of tension and apprehension [53]. A further terminological distinction derives from the subjective manifestations of anxiety, identifying the cognitive and somatic components of both state and trait [54]. Arousal accompanying somatic response reflects the intensity of the activation of the body and is conceptually independent of emotions. Nevertheless, states of peripheral autonomic arousal accompany emotional behaviour, physical exercise and cognitive effort. Data presented in this study demonstrated that at jump HR peaked, increasing by $180 \%$ as compared with the basal values. The A-A paralleled this trend increasing more than $400 \%$. These data are consistent with previous findings in parachutists $[41,19]$. Although there are no absolute levels of GSR, indicative of high workload or stress, higher GSR levels recorded during certain tasks suggest higher levels of stress. Comparing GSR data with A-A values may provide sufficient evidence that GSR data captured during the same experimental conditions are actually measuring stress. Changes in A-A concentrations were significantly related to the change in the GSR response produced at the jump. This relationship states for an augmented SAM response occurring during the task and represents evidence which has not been yet established. However, such a correlation was not confirmed for HR changes. Taken together, our data demonstrate that A-A and GSR changes may be considered a sort of "situational" stress and arousal. In our study we have also shown that in response to conditions that stimulate autonomic functions and adreno medullary secretion a concurrent activation of the HPA axis exists. Data presented in this study demonstrated that parachute jumping led to a strong response of Cort, which increased by $380 \%$ as compared with the basal values. Such an increase cannot be solely explained by the common knowledge that cortisol increase is linked to exercise. In fact, during parachute jumping the energetic component is rather low, as is the case of numerous sports consisting of short duration bouts of exercise. Moreover, according to Passelergue et al. [55], whatever the hour of sampling collection Cort was elevated, meaning that the psychological arousal linked to this condition acts on the HPA axis. However, no relationship between Cort and somatic or cognitive anxiety was noted, suggesting that this physiological measure is not a good index of stress during parachuting; in fact cortisol reactivity is not an important mechanism for observed cognitive stress vulnerability [56]. Although the HPA axis and the SAM are physiologically interconnected, they have different characteristic responses to stress and associations with emotions [57-59]. The HPA axis is activated by negative affect associated with stress, including fear and frustration, whereas the SAM system is related to effort and is valence non-specific $[60,61]$. Data presented in this study demonstrated that physiological responses showed a similar pattern of changes as a function of time to the jump, confirming their integrative role into a common system of arousal. The association of SAM with autonomic system activation resulted to be even closer than that of SAM with HPA activation. In fact, our data clearly demonstrated the relationship between GSR and A-A responses to stress, but failed to show association between Cort and A-A changes, even though both responses evidenced a similar trend. When evaluating HR and Cort together, as a combined physiological reactivity, no correlation was found at the average basal values (data not shown). Interestingly, they negatively correlated at jump, suggesting a relative dependence of the HPA axis and the autonomic nervous system in response to highly stressful situations. In fact, the increase in Cort levels upon touching the ground could be related to increased vagal modulation despite persistent sympathetic activation. Overall, these data indicated that while there is evidence for a common system of arousal, there is also evidence for a degree of independence among the different systems. Understanding the various manifestations of the anxiety is important to comprehend their influence on performance. A negative linear relationship with CA and a positive linear relationship with their personal capacity has been proved in relation to physical 
performance [62]. The SA also has a greater negative impact on events of short duration. The relationship between SA and performance is rather inverted U-shaped: to the increase in the SA is corresponding an increase in the level of arousal of the body and performance, up to an optimal point beyond which the performance lapses [63]. Data presented in this study demonstrated that parachutists reported a moderate level of anxiety and a higher level of S-C. According to Hanton et al. [64], cognitive and somatic symptoms individually perceived within personal control and thus interpreted to be facilitative were believed to increase confidence and performance. Therefore, the high S-C scores could be considered as an essential characteristic to protect parachutists against dysfunctional thoughts and feelings. Changes in Cort together with SA measures seems to provide a sensitive index of stress, as shown by the relationships between SA, CA and Cort $[65,66]$, or by the direction of anxiety components and cortisol [67]. Conversely, others studies found no relationship between anxiety intensity and Cort concentrations before competition [68,69]. Combining Cort, A-A changes and GSR data with SA scores, a significant association between A-A levels, GSR values and SA, but not CA scores emerged. Research points to cortisol reactivity as the mechanism for observed cognitive stress vulnerability [51]. However, our data do not support this hypothesis. Neither SA or CA, nor S-C correlated with Cort values, suggesting that this physiological measure is not as good as A-A to assess stress during parachuting. Finally, no correlation was observed between HR upon touching the ground and the SA scores.

Regression analyses showed positive relationships between S-C, SA, A-A concentrations and GSR data. Increases in A-A concentration and GSR were generally associated with increases in reported SA symptoms. This positive trend would support the view that arousal can result in increases in A-A levels and GSR. The S-C scale of the CSAI-2 positively correlated with the SA scale, but no correlation was found with CA scale, indicating that positive emotional elements were not influenced by CA levels. Taken together, these findings suggest that there is a different impact on anxiety and self-confidence levels when participants are required to approach jumping. Somatic anxiety and S-C are both correlated with SN and SAM activation and support coordinated regulatory mechanisms for endocrine and autonomic responses to stressor, contributing to the theory of interacting systems of cognitive evaluation, autonomic processes and hormonal functioning. Moreover, our findings indicate that GSR curves produce a better correspondence with the personality descriptions, than the curves of HR and Cort.

In conclusion, by combining the study of the physiological reactions and the emotional response, we obtained the first data on the relationship among hormonal, autonomic and both somatic and cognitive anxiety in subjects practicing sport parachuting. Data presented suggest that SA is correlated with SN and SAM activation, and that coordinated regulatory mechanisms for endocrine and autonomic responses to stressor may exist. Our findings also confirmed that GSR has the potential to provide researchers with a tool for objectively measuring stress during operational conditions. However, with respect to the presented results, a more proper elucidation of the overall relationships produced by the physiological measures and competitive state anxiety seems to be an important target for further research addressed to substantiate these observations. Therefore the present study should lead a contribute to the psychiatric literature because It was shown that extreme arousal, caused by parachute jumping, triggers substantial anticipated and post-activity CORT secretion. Empirical work in this domain is limited and this study is the first to demonstrate that intense acute stress effects become more pronounced when a learning task gains complexity. Finally, both the realistic stressor and the pathlearning task provide increased ecological validity to the present results, particularly for occupations for which path learning and way finding under pressure are paramount characteristics of job performance (e.g., the military, police officers, and emergency personnel).

\section{References}

1. Lundberg U, Frankenhaeuser M (1980) Pituitary-adrenal and sympathetic adrenal correlates of distress and effort. J Psychosom Res 24: 125-130.

2. Chrousos GP, Gold PW (1992) The Concepts of stress and stress system disorders: overview of physical and behavioral homeostasis. JAMA 267: 12441252.

3. Peters ML, Godaert GL, Ballieux RE, van Vliet M (1998) Cardiovascular and endocrine responses to experimental stress: effects of mental effort and controllability. Psycho-neuroendocrinology 23: 1-17.

4. Young EA, Abelson JL, Cameron, OG (2005) Interaction of brain noradrenergic system and the hypothalamic-pituitary-adrenal (HPA) axis in man Psychoneuroendocrinology 30: 807-814.

5. Messina G, De Luca V, Viggiano A, Ascione A, lannaccone T, et al. (2013) Autonomic nervous system in the control of energy balance and body weight: personal contributions. Neurol Res Int: 639280.

6. Goldstein DS ( 2003) Catecholamines and stress. Endocrine Regulations 37 69-80.

7. Messina G, Vicidomini C, Viggiano A, Tafuri D, Cozza V, et al. (2012) Enhanced parasympathetic activity of sportive women is paradoxically associated to enhanced resting energy expenditure. Auton Neurosci 169: 102-106.

8. Mason JW (1968) Organization of psychoendocrine mechanisms. Psychosom Med 30:565-808

9. Pilgrim K, Marin MF, Lupien SJ (2010) Attentional orienting toward socia stress stimuli predicts increased cortisol responsivity to psychosocial stress irrespective of the early socioeconomic status. Psychoneuroendocrinology 35 : 588-595.

10. Frankenhaeuser M (1980) Psychobiological aspects of life stress. In: Levine S Ursin K, (Eds) Coping and Health Plenum Press New York 203-223.

11. Gould D, Krane V (1992) The arousal-athletic performance relationship: current status and future directions. In: Horn T (Ed.) Advances in Sport Psychology Human Kinetics Publishers Inc IL 119-142.

12. Monda M, Messina G, Scognamiglio I, Lombardi A, Martin GA, et al. (2014) Short-term diet and moderate exercise in young overweight men modulate cardiocyte and hepatocarcinoma survival by oxidative stress. Oxid Med Cell Longe: 131024

13. Di Bernardo G, Messina G, Capasso S, Del Gaudio S, Cipollaro M, et al. (2014) Sera of overweight people promote in vitro adipocyte differentiation of bone marrow stromal cells. Stem Cell Res Ther 5: 4

14. Esposito M, Serpe FP, Diletti G, Messina G, Scortichini G, et al. (2014) Serum levels of polychlorinated dibenzo-p-dioxins, polychlorinated dibenzofurans and polychlorinated biphenyls in a population living in the Naples area, southern Italy. Chemospherev 94: 62-69

15. Frijda NH (1988) The laws of emotion. Am Psychol 43: 349-358.

16. Kirschbaum C, HellhammerDH(1994) Salivary cortisol in psychoneuroendocrine research: recent developments and applications. Psychoneuroendocrinology 19: 313-333.

17. Nater UM, Rohleder N, Gaab J, Berger S, Jud A, et al. (2005) Human salivary alpha-amylase reactivity in a psychosocial stress paradigm. Int J Psychophysiol 55: 333-342.

18. Granger DA, Kivlighan KT, el-Sheikh M, Gordis EB, Stroud LR (2007) Salivary alpha-amylase in bio-behavioral research: recent developments and applications. Ann NY Acad Sci 1098: 122-144.

19. Chatterton RTJr, Vogelsong KM, Lu YC, Hudgens GA (1997) Hormonal responses to psychological stress in men preparing for skydiving. J Clin Endocrinol Metab 82: 2503-2509.

20. Skosnik PD, Chatterton RTJr, Swisher T, Park S (2000) Modulation of 
Citation: Messina G, Avalenzano A, Moscatelli F, Triggiani Al, Capranica L, et al. (2015) Effects of Emotional Stress on Neuroendocrine and Autonomic Functions in Skydiving. J Psychiatry 18: 280 doi: 10.4172/2378-5756.1000280

Page 6 of 7

attentional inhibition by norepinephrine and cortisol after psychological stress. Int J Psycophysiol 36: 59-68.

21. Monda M, Amaro S, Sullo A, De Luca B (1994) Posterior hypothalamic activity and cortical control during the PGE1 hyperthermia. Neuroreport 6: 135-139.

22. Monda M, Pittman QJ (1993) Cortical spreading depression blocks prostaglandin E1 and endotoxin fever in rats. Am J Physiol 264(2 Pt 2): R456-R459.

23. Rohleder N, Nater UM, Wolf JM, Ehlert U, Kirschbaum C (2004) Psychosocia stress- induced activation of salivary alpha-amylase: an indicator of sympathetic activity? Ann NY Acad Sci 1032: 258-263.

24. Gordis EB, Granger DA, Susman EJ, Trickett PK (2006) Asymmetry between salivary cortisol and alpha-amylase reactivity to stress: relation to aggressive behavior in adolescents. Psychoneuroendocrinology 31: 976-987.

25. Nater UM, La Marca R, Florin L, Moses A, Langhans, W, et al. (2006) Stressinduced changes in human salivary alpha-amylase activity associations with adrenergic activity. Psychoneuroendocrinology 31: 49-58

26. Yamaguchi M, Kanemori T, Kanemaru M, Takai N, Mizuno Y, et al. (2004) Performance evaluation of salivary amylase activity monitor. Biosens Bioelectron 20: 491-497.

27. Kivlighan KT, Granger DA (2006) Salivary alpha-amylase response to competition: Relation to gender, previous experience, and attitudes. Psychoneuroendocrinology 31: 703-714.

28. Chiodo S, Tessitore A, Cortis C, Cibelli G, Lupo C, et al. (2009) Stress-related hormonal and psychological changes to official youth Taekwondo competitions. Scand J Med Sci Sports Dec 18 [Epub ahead of print].

29. Chatterton RTJr, Vogelsong KM, Lu YC, Hudgens GA (1997) Hormonal responses to psychological stress in men preparing for skydiving. J Clin Endocrinol Metab 82: 2503-2509.

30. Wetherell MA, Crown AL, Lightman SL, Miles JN, Kaye J, et al. (2006) The four-dimensional stress test: psychological, sympathetic-adrenal-medullary, parasympathetic and hypothalamic-pituitary-adrenal responses following inhalation of 35\% CO2. Psychoneuroendocrinology 31: 736-747.

31. Perroni F, Tessitore A, Cortis C, Lupo C, D'artibale E, et al. (2009) Energy Cost and Energy Sources During a Simulated Firefighting Activity. J Strength Cond Res Dec 1 [Epub ahead of print].

32. Fenz WD, Epstein S (1967) Gradients of a physiological arousal of experienced and novice parachutists as a function of an approaching jump. Psychosom Med 29: 33-51.

33. Morris LW, Engle WB (1981) Assessing various coping strategies and their effects on test performance and anxiety. J Clin Psychol 37: 165-171.

34. Martens R, Burton D, Vealey RS, Bump LA, Smith DE (1990) Development validation of the Competitive State Anxiety Inventory-2. In: Martens R, Vealey RS, Burton D (Eds.), Competitive anxiety in sport, Human Kinetics Publishers Inc, Champaign IL 117-190.

35. Oltras CM, Mora F, Vives F (1987) Beta-endorphin and ACTH in plasma: effects of physical and psychological stress. Life Sci 27: 1683-1686.

36. Mutti A, Ferroni C, Vescovi PP, Bottazzi R, Selis L, et al. (1989) Endocrine effects of psychological stress associated with neurobehavioral performance testing. Life Sci 44: 1831-1836.

37. Gerra G, Zaimovic A, Mascetti GG, Gardini S, Zambelli U, et al. (2001) Neuroendocrine responses to experimentally-induced psychological stress in healthy humans. Psycho-neuroendocrinology 26: 91-107.

38. Noel GL, Dimond RC, Earll JM, Frantz AG (1976) Prolactin, thyrotropin, and growth hormone release during stress associated with parachute jumping. Aviat Space Environ Med 47: 534-537

39. Anfilogoff R, Hale J, Nattrass M (1987) Physiological response to parachute jumping. Br Med J 295: 415

40. Dugue B, Leppanen EA, Teppo AM, Fyhrquist F, Grasbeck R (1993) Effects of psychological stress on plasma interleukins-1 beta and 6, C-reactive protein tumour necrosis factor alpha, anti-diuretic hormone and serum cortisol. Scand J Clin Lab Invest 53: 555-561.

41. Roth WT, Breivik G, Jorgensen PE, Hofmann S (1996) Activation in novice and expert parachutists while jumping. Psychophysiology 33: 63-72.
42. Schedlowski M, Tewes $U$ (1992) Physiological arousal and perception of bodily state during parachute jumping. Psychophysiology 29: 95-103.

43. Jung K, Schulze J (1982) Sports-medical studies on parachute jumpers with particular reference to the behavior of heart rate. Biotelem Patient Monit 9 238-250.

44. Viggiano A, Vicidomini C, Monda M, Carleo D, Carleo R, et al. (2009) Fast and low-cost analysis of heart rate variability reveals vegetative alterations in noncomplicated diabetic patients. J Diabetes Complications 23: 119-123.

45. Monda M, Messina G, Vicidomini C, Viggiano A, Mangoni C, et al. (2006) Activity of autonomic nervous system is related to body weight in pre-menopausal, but not in post-menopausal women. Nutr Neurosci 9: 141-145.

46. Richter SD, Schürmeyer TH, Schedlowski M, Hadicke A, Tewes U, et al. (1996) Time kinetics of the endocrine response to acute psychological stress. J Clin Endocrinol Metab 81: 1956-1960.

47. De Luca V, Viggiano E, Messina G, Viggiano A, Borlido C, et al. (2008) Peripheral amino Acid levels in schizophrenia and antipsychotic treatment Psychiatry Investig 5: 203-208.

48. Viggiano A, Nicodemo U, Viggiano E, Messina G, Viggiano A, et al. (2010) Mastication overload causes an increase in O2- production into the subnucleus oralis of the spinal trigeminal nucleus. Neuroscience 166: 416-421.

49. Monda M, Viggiano A, Viggiano A, Mondola R, Viggiano E, et al. (2008) Olanzapine blocks the sympathetic and hyperthermic reactions due to cerebral injection of orexin A. Peptides 29: 120-126.

50. Robazza C, Bortoli L (2007) Perceived impact of anger and anxiety on sporting performance in rugby players. Psychology of Sport and Exercise 8: 875-896.

51. Mujica-Parodi LR, Renelique R, Taylor MK (2009) Higher body fat percentage is associated with increased cortisol reactivity and impaired cognitive resilience in response to acute emotional stress. Int J Obesity 33: 157-165.

52. Mandler MB (1984) Temporal frequency discrimination above threshold. Vision Res 24: 1873-1880.

53. Martens R, Bump L (1988) Coaches guide to sport psychology. Human Kinetics Publishers Inc Champaign II.

54. Pancheri P, Bressa GM (1990) Ansia e dolore. Wyeth Publisher Rome.

55. Passelergue P, Robert A, Lac G (1995) Salivary cortisol and testosterone variations during an official and stimulated weight-lifting competition. Int $J$ Sports Med 16: 298-303.

56. Fernandez-Fernandez J, Boullosa DA, Sanz-Rivas D, Abreu L, Filaire E, et al. (2015) Psychophysiological stress responses during training and competition in young female competitive tennis players. Int J Sports Med 36: 22-8.

57. Schommer NC, Hellhammer DH, Kirschbaum C (2003) Dissociation between reactivity of the hypothalamus-pituitary-adrenal axis and the sympatheticadrenal-medullary system to repeated psychosocial stress. Psychosom Med 65: $450-460$

58. Monda M, Viggiano A, Viggiano A, Fuccio F, De Luca V (2004) Injection of orexin $A$ into the diagonal band of Broca induces sympathetic and hyperthermic reactions. Brain Res 1018: 265-271.

59. Monda M, Amaro S, Sullo A, De Luca B (1995) Injection of muscimol in the posterior hypothalamus reduces the PGE1-hyperthermia in the rat. Brain Res Bull 37: 575-580

60. Frankenhaeuser $M$ (1982) Challenge-control interaction as reflected in sympathetic-adrenal and pituitary-adrenal activity: comparison between the sexes. Scand J Psychol 1: 158-164.

61. Monda M, Viggiano A, Viggiano A, Viggiano E, Messina G, et al. (2006) Quetiapine lowers sympathetic and hyperthermic reactions due to cerebral injection of orexin A. Neuropeptides 40: 357-363.

62. Burton, D (1988) Do anxious swimmers swim slower? Reexamining the elusive anxiety performance relationship. J Sport and Exercise Psychol 10: 45-61.

63. Hardy $L$ (1999) Stress anxiety and performance. J Sci Med in Sport 2: 227-233.

64. Hanton S, Mellalieu SD, Hall R (2004) Self-confidence and anxiety interpretation: A qualitative investigation. Psychology of Sport and Exercise 5: 477-495.

65. Mckay JM, Selig SE, Carlson JS, Morris T (1997) Psychophysiological stress in elite golfers during practice and competition. Aust J Sci Med Sport 29: 55-61.

66. Filaire E, Bernain X, Sagnol M, Lac G (2001) Preliminary results on mood state 
Citation: Messina G, Avalenzano A, Moscatelli F, Triggiani Al, Capranica L, et al. (2015) Effects of Emotional Stress on Neuroendocrine and Autonomic Functions in Skydiving. J Psychiatry 18: 280 doi: 10.4172/2378-5756.1000280

Page 7 of 7

salivary testosterone: cortisol ratio and team performance in a professional soccer team. Eur J Appl Physiol 86:179-184

67. Eubank M, Collins D, Lovell G, Dorling D, Talbot S (1997) Individual temporal differences in pre-competition anxiety and hormonal concentration. Pers Indiv Differ 23:1031-1039.
68. Singh A, Petrides JS, Gold P, Chrousos G, Deuster P (1999) Differentia hypothalamic-pituitary-adrenal axis reactivity to psychological and physical stress. J Endocr Metab 84: 1944-1948.

69. Thatcher J, Thatcher R, Dorling D (2004) Gender differences in the precompetition temporal patterning of anxiety and hormonal responses. J Sport Med Phys Fitness 44: 300-308. 